2021 • Fall - Güz • Volume - Cilt: 12 • Issue - Sayı: 47

\title{
Teknolojinin Neresindeyiz? Bilim ve Kurguda Gelecek-Zaman Tasavvurlari*
}

Sertaç Timur DEMIR, Gümüşhane Üniversitesi, Radyo Televizyon ve Sinema, Doç. Dr., stdemir@yahoo.com, (D) 0000-0002-9420-9416

$\ddot{O Z Z}$

Bu makalede bilim ve kurgu portreleri üzerinden bir tür "yaşanan gelecek" sorgulaması yapılmaktadır. Çalışmada teknolojinin engin dünyasına sosyal bilimlerin eleştirelliğiyle yaklaşan düşünürlerin izleri varsa da; bu teorik arkaplan, bu makalede teknolojinin çă̆cıl dönüşümü ve felsefi yansımalar gereğince yeniden mercek altına alınmaktadır. Hiç şüphesiz tüm küreyi etkisi altına alan ve birçok teknolojik deneyimi meşrulaştıran Covid-19 salgını, bu sorgulamayı doğru zamanlı bir girişim yapmaktadır. Nitekim uzay, zaman, savaş, makineler, robotlar, yapay zekâ, veri, gen, biyo-teknoloji, mikroplar, virüsler, beden, sağlık, ölüm/süzlük, hafıza, siber-dünya, otorite, otomasyon, mekân, iklim, demografi, taşıtlar ve aygıtlar gibi bilim ve kurgunun kadim temaları, bu salgınn ellerinde biz modernleri izleyici olmaktan çıkarıp, 'kendine tanık' yapmıştır. Tam da bilim kurguda vücut bulan bu tanıklığa belli bir mesafeden bakan bu makalede, modern dünyanın gözünü karartıp girdiği loş tünelin görünümleri incelenmektedir. Bu amaçla bilimin kurguyla, bilim kurgunun gerçekle, gerçeğin gelecekle; araçların modern insanla ve felsefenin fütürizmle ilişkisi ele alınmaktadır.

Anahtar : : Teknoloji, Bilim Kurgu, Gelecek, Fütürizm, Beşerî Bilimler

Kelimeler

\section{Where Are We in Technology? Future-Time Design in Science and Fiction}

ABSTRACT

In this article, a kind of "living future" issue is questioned through science and fiction portraits. Although there are traces of thinkers who approach the vast world of technology with the criticism of humanities; this theoretical background is brought into focus in this article in accordance with the modern transformation of technology and its philosophical reflections. Undoubtedly, the Covid-19 epidemic, which affects the entire globe and legitimizes many technological experiences, makes this questioning a timely initiative. As a matter of fact, ancient themes of science and fiction such as space, time, war, machines, robots, artificial intelligence, data, gene, bio-technology, microbes, viruses, body, health, death / immortality, memory, cyber-

"Bu makale, Yakın Doğu Üniversitesi İletişim Araştırmaları Merkezi'nin 14-16 Haziran 2021 tarihinde düzenlendiği I. Uluslararası Sinema Sempozyumu'nda sunulmuş “Teknolojikleşen Kültürün Sinemasal İzdüşümleri: Gelecek-Zaman Tasarımcısı Olarak Bilim Kurgu Filmleri” başlıklı bildirinin geliştirilmiş halidir. 
world, authority, automation, space, climate, demography, vehicles and devices have made modern people 'witnesses to themselves' rather than viewers in the hands of this epidemic. This article, which looks at this testimony embodied in science fiction from a close distance, examines the appearance of the dim tunnel through which the modern world enters in a dark way. For this purpose, the relationship between science and fiction, between science fiction and reality, between reality and future, between tools and modern people, and between philosophy and futurism is debated.

Keywords : $\quad$ Technology, Science Fiction, Future, Futurism, Humanities

\section{EXTENDED ABSTRACT}

This study focuses on science / fiction from both its scientific and fictional perspectives and its relationship with reality or the future. According to this approach, a film is not just a film. It is the projector of the social (Diken and Laustsen, 2016). Especially techno-scientific activities are often completed in the fantastic world of science fiction. On the one hand, science fiction presents the slow-motion of rapid transformation; on the other hand, it prepares visions and templates for the future. Therefore, in this article, the pessimistic texture of the future view and the connection of humanities with futuristic imaginations are questioned. In this context, it is assumed that this whole process takes place between the dichotomy of bondage and liberation, so much so that the real is now fictional; science is now instrumental; tools are now indispensable.

Despite all the marginal narratives and appearances of science fiction, it can be defined as a kind of 'contemplation of the future' that brings together the curiosity of humanity with the desire for invention. As a matter of fact, there is always a scientific tendency behind the logic that guides this genre. Leonhard also sees it as the truth of science (2018, p. 28). With this aspect, it can also be claimed that science fiction, in the face of the chaotic post-pandemic world, goes beyond being a mere 'prophecy' and takes on the role of a kind of time designer (Demir, 2021, p. 91). Besides, the imaginary universe in science fiction does not destroy reality itself; on the contrary, it reproduces and directs it. Science fiction is a projection of current reality and a dreamy and pessimistic expression of the world of invention.

Fragments of time become more and more obscure as emotions are emptied in the envelopment of tools and actions that keep consciousness open are completely trapped in routines. This is why it is one of the most well-known discourses of the modern age: "time passes quickly". This situation necessarily meets with a future pessimism that glorifies nostalgia for the past at some point. Because of this, some thinkers think that the future is shortened to the extended present (Chul-Han, 2017, p. 39), some think that the future has already come before it is necessary (Toffler, 2011, p. 15), some think that the future will soon be history (Goodman, 2016, in George Carlin). p. 555), some say that the future has come but 
not yet given to everyone (William Gibson in Goodman, 2016, p. 57), some say that the future has already ended (Anders, 2018b, p. 342) and is already living in a kind of futurity (Anders, 2018a, p. 340).

Technology instrumentalises its users. Therefore, Leonhard ironically defines humans as the reproductive organs of technology $(2018$, p. 83). This change of place and role, which has turned into abuse, condemns the people of the age to be an output of technology, either as a producer or as a consumer. Futurism, the fundamental perspective of science and fiction, often puts technology at the centre of the transformation for the future. In many dystopian narratives, there are reflections of the catastrophe caused by the devices that enter daily life in an innocent silence and get out of control at an unpredictable stage. It is obvious that every unexpected change that arises in the world of vehicles radically affects the functioning of the social order. Futuristic science fiction culture adapts user-people to the future by depicting all the real or surreal extremes of the global vision. On the other hand, the humanities invite them to slow down. This slowdown includes actions of thinking, anticipating possible consequences, questioning, confronting, and revising.

The man of the age is, at this moment, both the "viewer" and the "watched" of the world of images, just like the pixels that make up the photographic frame but cannot produce meaning on their own. As a spectator character and object, human is approved to the extent that he sees and appears and believes that he exists. As a result of this, images and reality are displaced. The connection between the moderns to their own existence is no longer a direct affinity, it represents a huge distance shaped in the hands of technological design and stacked with tools. Perhaps for this reason, the modern individual spends his energies mostly on vehicles that carry the debris of the outside world. Again, perhaps this is why he concentrates so much on the narratives of science and fiction - again as an external action - in order to sense the new futuristic reality that surrounds him and the future he is deeply involved in.

\section{GİRIŞ: Bilim / Kurgunun Gösterdikleri}

“Bir şey söylemem gerekmiyor. Yalnızca göstermeliyim".

Walter Benjamin (Pasajlar'dan)

Bu çalışma bilim kurguya hem bilimsel hem de kurgusal ayakları üzerinden ve gerçekle veya gelecekle kurduğu ilişki bakımından odaklanmaktadır. Nitekim bilim kurgu, bir anlatı türü olarak da araçlarla iç içe geçmiş ve temel göstergesi teknoloji olan çağımızın göstergelerinden biridir. Bu yaklaşıma göre bir film yalnızca bir film değildir. $\mathrm{O}$, toplumsalın projektörüdür (Diken ve Laustsen, 2016). Belki de bir adım ötede bu çağın gerçekliği, sinemasal kurgunun izini sürmektedir. Özellikle tekno-bilimsel faaliyetler çoğu kez bilim kurgunun fantastik dünyasında tamamlanmaktadır. Bilim kurgu bir yandan yaşanan hızlı dönüşümün ağır çekimini sunmakta, diğer yandan geleceğin önüne tasavvurlar ve şablonlar 


\section{AJIT-e Bilişim Teknolojileri Online Dergisi \\ Academic Journal of Information Tecnology \\ 2021 Fall/Güz - Cilt/Vol: 12 - Sayı/Issue: 47 \\ doi) 10.5824/ajite.2021.04.003.x}

hazırlamaktadır. Makalenin temel argümanlarından bir diğeri de, hem birlikte hem de ayrı ayrı olarak bilim ve kurgunun modern kültürün eşzamanlı vaat ve kaygılarını bünyesinde taşıdığıdır. Bir beşerî bilimsel girişim olarak bu makalede, geleceğe bakışın karamsar dokusu ve beşeri bilimlerin fütürist tasavvurlarla bağlantısı sorgulanmaktadır. Bu bağlamda, tüm bu sürecin esaret ve özgürleşme ikilemi arasında cereyan ettiği varsayılmakta ve gerçeğin artık kurgusal; bilimin artık araçsal; araçların ise artık olmazsa olmaz bir değere ulaştığı öne sürülmektedir.

Bilim kurgu olanca marjinal anlatı ve görünümlerine rağmen; insanlığın merak duygusunu buluş arzusuyla buluşturan bir tür 'gelecek tasavvuru' olarak tanımlanabilir. Nitekim bu türe yön veren mantığın ardında daima bilimsel bir eğilim bulunmaktadır. Leonhard da bilim kurguyu, bilimin gerçeği olarak görmektedir (2018, s. 28). Bu yönüyle, özellikle pandemi-sonrası kaotik dünyanın karşısında bilim kurgunun salt bir 'kehanetçi' olmanın ötesine geçerek, bir tür zaman tasarımcısı rolüne soyunduğu da iddia edilebilir (Demir, 2021, s. 91). Gerçekten de bilim kurgu, tıpkı ilk taşınabilir iletişim cihazlarının Uzay Yolu'nda görülmesi gibi, teknoloji uzmanlarına yeni şeyler icat etmenin vizyonunu sunmaktadır (Standage, 2021, s. 23). Jacques Baudou'ya göre bilim kurgu, gerçeğe yönelik bir duruş ve hayal dünyasının ifşasıdır (2005, s. 10). Öte yandan bilim kurgudaki hayal evreni, gerçeği yıkmamakta; yeniden üretip ona yön vermektedir. Başka bir deyişle o, geçerli gerçekliğin bir izdüşümü ve icatlar dünyasının bir dışavurumudur. Öyle ki, bir zamanlar bilim kurgu olarak kabul edilen ifadelerin, çoktan kanıtlanmış bilimsel olgulara dönüştüğü bir noktada olduğumuz bile öne sürülebilmektedir (Leonhard, 2018, s. 177).

Günther Anders de bilim kurguyu, teknolojinin angaje sanatı olarak tanımlamaktadır (2018b, s. 172). Fakat burada bilim kurgunun mu teknolojiye, teknolojinin mi bilim kurguya angaje olduğu, yani hangisinin öncü olduğu konusu tartışmalıdır. Bilim kurguda gösterilen fanteziler gerçeğe ve geleceğe göz kırpmakta ve zamanın akışını kendi mecrası içinde ayartmaktadır. Bilim kurgunun kadim temalarına bakıldığında, onun bu düşünsel kuşatıcılığ daha iyi anlaşılmaktadır. Uzay ve uzay yolculuklarından meçhul dünyalara ve yaratıklara, zaman yolculuğundan kıyamet senaryolarına, terör ve istiladan savaş teknolojilerine, robotlardan transhümanizme, genetikten virüslere, siber-alemden aşkın modellemelere, iklimden tüketimciliğe, yeni kentlerden otomasyona, gözetimden gösteriye, enerjiden ölümsüzlük istencine yaşamın hemen her alanına göndermeleri olan bilim kurgu tarihe, topluma, biyolojiye ve en önemlisi de "İnsana ne oluyor" sorusuna yanit aramaktadır. "Bilim kurgu, dünya ile ilgili eleştirel bir düşlem evreni olmaktan çıkıp günümüzde yapılan bir deney, toplumlarımızın yakasından düşmeyen birtakım sorunların hayali bir projeksiyonu haline gelmiştir. Dünyanın kendisi bir bilim kurgu evrenine dönüşmüştür" (Bukatman'dan, 1993 akt. Le Breton, 2016, s. 169). 
Bizzat dünya bilim kurgu yazarlarıyla haksız rekabete girmiş durumdadır; onların varsayımlarını abartmakta, hatta bazen doğrudan doğruya onların hayallerinden çıkmış gibi görünen toplumsal ve teknolojik bir çevreyi gerçek kılmaktadır: Makinenin insanlaşması, insanın şeyleşmesi, insanın bedeninin ya da ona sindirilmiş bileşenlerin tohum gibi yayılması, vicdansız şirketlerin teknolojiyi saptırmaları, insan zihninin dijitalleşmesi vb. Bilim kurgunun dünyası artık gerçeğe karşıt olmadığı gibi, bazen de çağdaş hayatın sosyolojik temellerinin apaçık ortaya konulmuş hali gibi görünmektedir. Geleceğin kolektif yönelimlerini belirleyen hayal gücüne el konulması hem gelişmenin en elverişli yolunu hem de toplumsal dokuya yansımanın yolunu bilim kurguda bulmaktadır. Bilim kurgu, yakın gelecek senaryolarını deneyimlemekte ve şimdiki zamanda zaten etkili olan süreçleri aydınlatmaktadır (Le Breton, 2016, s. 170).

Bilim kurgu, bir sanat geleneği olarak kökleri en fazla edebiyatta olan, ancak bugün kitlelerle en popüler anlamda sinema yoluyla buluşan bir türdür. Bu uzamda uzun ve derin metinlerden çok; kısa ve göz alıcı görsellerin hükmü geçmektedir. Öyle ki, sinemanın (özelde Hollywood'un) izlerini bilinçaltından ve limbik sistemden silmek, Harari'nin belirttiği gibi (2018, s. 230), basitçe 'sil' tuşuna basarak mümkün değildir. Modern çağın tüm meselesi, dünyanın bir imge/resim olarak fethedilmesiyse de (Heidegger ve Lovitt) 1977); bu fetih, söz konusu görsel parıltıların anlık dışavurumlarının artık çok ötesindedir. Çünkü her görüntü, düşünsel ve duygusal süreçleri yöneten- bir anlatıdır (Barthes, 2015, s. 60). Başka bir ifadeyle, görsellik olarak sinema ya da resim olarak dünya, bazen biri diğerinin metaforu olarak gerçekliğin şablonlaştırıldığı ve izleyici-özneye sindirildiği manipülatif bir işleyişi ifade etmektedir. Kracauer da görüntü yığınının şiddetli saldırılarının farkındalığı dumura uğratan bir tarafı olduğundan bahsetmektedir (2011, s. 34-35). Buradaki saldırı, görüntünün çokluğundan ziyade çokluğun, arada düşünmeye fırsat vermeyecek bir ardardalık -hatta tuhaf bir acelecilik dokusu taşımasıyla ilişkili olabilir. Belki de bu nedenle Chul-Han (2019, s. 56), Marcel Proust'un düşüncesinden esinlenerek, görsel bir zaman olarak acelecilik çağının sinematografik nitelik taşıdığını ve dünyayı sinema perdesinde art arda dizilmiş şeylere doğru hızlandırdı ğ belirtmektedir.

Öte yandan, özellikle Horkheimer ve Adorno'nun (1996) kültür endüstrisinin yeniden üretimini temin etmekle tenkit ettiği [popüler] sinemanın aksine, 'sanat olarak sinema'ya genel anlamda ise sanata geçici olandaki kalıcılığı bulma rolünü yükleyen bakış açıları da söz konusudur (Gadamer, 2015, s. 81). Bu misyon, elbette sinemayı yalnızca görsel değil; duyusal bir sanat olarak okumakla ilgilidir (Ranciere, 2016, s. 9). Sanatın imkân ve amacı konusu bir yana, Baudrillard'a göre sinema yaşamı senaryolaştırmak suretiyle, yaşanacak olanın önizlenimlerini sunmakta (1998, s. 75), bir bakıma, yaşamla arasındaki [gerekli] mesafeyi ve soyutlamayı askıya almaktadır (2013, s. 117). Üstelik bunu gerçeklikten daha pahalıya mal olan bir kurgu yoluyla (Baudrillard, 2006, s. 74) ve herhangi bir ima, yanılsama, boşluk, eksilti veya sessizlik bırakmayan bir hiperteknik, hiperetkililik ve hipergörünürlük düzeyinde yapmaktadır (Baudrillard, 2010, s. 29). 


\section{AJIT-e Bilişim Teknolojileri Online Dergisi \\ Academic Journal of Information Tecnology \\ 2021 Fall/Güz - Cilt/Vol: 12 - Sayı/Issue: 47 \\ doi) 10.5824/ajite.2021.04.003.x}

Harari de (2018, s. 227), makine öğrenmesi teknolojisi ya da genetik mühendisliği konularında yayımlanan son makalelerin pek az insan tarafından okunduğunu, bunun yerine Matrix ve Her gibi filmlerle Westworld ve Black Mirror gibi dizilerin izlenerek bir anlamlandırma çabasının olduğunun altını çizmektedir. Bir adım ötede filmsel anlatı, gerçeği ve geleceği kendisi gibi olmaya çağırmaktadır. Nitekim bir filmin geliştirdiği gelecek-zamankurgusu, esasında örtük bir iştahla "dünya tam da böyle olsun" dileği taşımaktadır. Film temaları ve filmlerde gösterilenler, bu anlamda, salt basit önermeler değil; onaylanmaya açık harekete-geçirici öneriler de sunmaktadır. Bilim kurgunun gücü tam da burada saklıdır: bu filmler, gösterdiklerinin bilimselliğe ya da toplumsallı̆̆a uygun ve uyumlu oluşlarıyla değil; bunlara ufuk çizmeleriyle değer ve popülerlik kazanmaktadırlar. Sinemasal görüntüler, büyük yönetmen Tarkovski'ye göre (2000, s. 132), gerçek düşüncesini ifade ettikleri için bizzat yaşamdan bile daha zengindirler. Filmler kendi dünyalarını kurarken; yaşamda kesin olarak varolmayan bir tür önceden-belirlenebilirlik ve belirleyebilirlik nitelikleriyle beyazperdenin dışındaki dünyayı da inşa etmektedirler. Fakat her inşa bir bakıma imhadır da; gerçeğin ve geleceğin imhası.

\section{GELECEĞE DAİR KARAMSAR BAKIŞIN ARKA PLANI}

Bilim kurgu biz [izleyicilere] gerçeği ve geleceği gösterirken, esasında şimdinin uzantılarını sezdirmekte ve dolayısıyla geleceğe yönelmiş gibi görünen eylemsel odağ şimdi'nin üzerinde toplamaktadır. Carl Sagan'ın tespit ettiği gibi (akt. Goodman, 2016, s. 452) bilim ve teknoloji etrafında örülen ve zihinsel karmaşaya neden olan eşzamanlı güç ve bilinmezlik perdesi, biraz da bilim kurgunun ellerinde berraklık kazanmaktadır. Başka bir ifadeyle bilim kurgu, fazlaca içine düşüldüğü için belirsizleşen katastrofinin hem örüldüğü hem de çözüldüğü uzama evrilmektedir. Onun bir öngörü olarak hakikate mutlak isabet etme şartı bulunmadığı gibi, tüm ilgisi tahmin yürütmeden ziyade tasarı geliştirme üzerine toplanmıştır. Bunu yaparken, teknolojik ilerlemeye olabildiğince çekinceli, daha açıkçası karamsar yaklaşmaktadır. Nitekim sinemanın ihtiyaç duyduğu çatışma noktası, böylesi bir karamsarlığa ihtiyaç duymaktadır. Alvin Toffler'e göre (1991, s. 81) bu kötücül varsayım esasen çağın modasıdır. Özellikle tekinsiz araçların gölgesinde yükselen bu moda, şimdiki zamanı felaket senaryolarıyla kirletirken; geçmişe ise -sorunlu bir şekilde- nostaljik bir olumlamayla yaklaşmaktadır.

Duyguların araçların kuşatıcılığında içinin boşaltılması ve bilinci açık tutan eylemlerin tümüyle kısır rutinlere hapsolması sonucunda zamanın fragmanları da iyiden iyiye belirsizleşmektedir. Modern çağın en bilindik söylemlerinden biri bu nedenle: "Zaman hızlı geçiyor"dur. Bu durum, mutlaka bir noktada geçmişe özlemi yücelten bir gelecek pesimizmiyle buluşmaktadır. Böyle olduğu için düşünürlerden kimisi geleceğin uzatılmış şimdiye kısaltıldı̆̆ını (Chul-Han, 2017, s. 39), kimisi geleceğin gereğinden önce zaten geldiğini 
(Toffler, 2011, s. 15), kimisi geleceğin yakında tarih olacağını (Georg Carlin'den akt. Goodman, 2016, s. 555), kimisi geleceğin geldiğini ama henüz herkese verilmediğini (William Gibson'dan akt. Goodman, 2016, s. 57), kimisi ise geleceğin çoktan sona erdiğini (Anders, 2018b, s. 342) ve zaten bir tür geleceksizlik içinde yaşandığını (Anders, 2018a, s. 340) ileri sürmektedir.

Tarihin her saniyesi geleceğe doğru yönelen bir dizi yolların kavşağıdır. Yol ayrımlarında olmak insan toplumunun var olma şeklidir... Gelecek, tam olarak insan seçimi ve eylemine yeteri kadar yer bırakmasıyla geçmişten ayrılır. Seçim olmadan gelecek yoktur -seçim sadece seçimden kaçınmaya ve onun yerine sürüklenmeye dayanıyor bile olsa. Eylem olmadan da gelecek yoktur -eylem alışılmış kalıpları terk etmiyor ve olduğundan farklı olabileceği ihtimalini kabul etmiyor bile olsa. Bu nedenden dolayı, gelecek her zaman henüz olmamış, belirsiz ve açık uçludur (Bauman, 2015, s. 122).

Öngörülmezliğin seçme arzusuna temas ettiği nokta olan gelecek figürü, Chul-Han'ın tespit ettiği gibi (2019, ss. 112-113), ona ancak yüksek vaatler yüklenerek belli bir somutluğa kavuşabilmektedir. Başka bir ifadeyle, geleceğin kestirilemeyen can sıkıcı tabiatına karşı çözüm olarak hep daha iyi bir hayat beklentisi empoze edilmektedir. Doğrusu bu beklenti, tüketimci kültürün de temel motivasyonudur. Bu kültürde kişiler, pürüzsüz bir geçmiş düşüncesinin zıttı olarak, geleceğin önlem alınması şart bir kötüleşme içinde olduğuna inandırılmaktadırlar. Belki de zaman ilerledikçe, işler gerçekten kötüye gitmekte, birçok bilim ve teknoloji teorisyeninin öne sürdüğü gibi insan iradesi araçların egemenliği altında buharlaşmaktadır. Öte yandan, her çağın kendini tarihin dönüm noktası olarak görme / gösterme eğilimi de söz konusudur.

Örneğin Toffler'e göre (2008, s. 434), yaşanmakta olan dönüşüm basit bir teknoloji devrimi değil; mutlak hakimiyetin esas olacağı yepyeni bir uygarlığın gelişidir. John Lukacs da çağın sonunda olduğuna inanıp, bu sona erişin ruhlarda hissedildiğini ama bilincin yüzeyine henüz çıkmadığını düşünenlerdendir (2018, s. 46). Harari'nin deyimiyle tüm eski anlatıları ufalayan bu eşsiz değişimler şafağında onların yerine geçecek geçerli bir anlatı tam olarak ortaya da çıkmamıştır (2018, s. 239). Dahası önümüzdeki yirmi yıllık değişimin geçmiş üç yüz yıldan daha büyük olacağ1 tahmin edilmektedir (Leonhard, 2018, s. 19). Üstelik insanlığın bu denli hızlı ilerleme adına attığı her adım, onu kendi yok oluşuna götürecek devasa bir hırs, enerji ve dehayla doludur (Baudrillard, 2006, s. 27). Rene Guenon'a göre de (2019, s. 55), karanlık çağın en karanlık dönemi olan bu çağ basit bir doğrulmayı değil; bütünsel bir yenilenmeyi, ama düzensizlik ve bunalım üreten bir yenilenmeyi çağrıştırmaktadır.

Geleceğe dair karamsar ve hatta umutsuz yaklaşımı salt öznel bir algılamaya ya da çağlara özgü yaygın bir paranoyaya dayandırmak elbette mümkündür. Ancak böylesi bir tez, ilgili melankolinin entelektüel tarafını göz ardı etmek olacaktır. Nitekim Schmid'in yakaladığ gibi (2020, ss. 90-91), gelecek zaman melankolisi, eleştirel mesafenin üretilmesine, olası tehditkâr bir durumun algılanmasına ve alışkanlıklar içinde görünmezleşen bir şeyin yeniden sorgulanmaya açılmasına da hizmet etmektedir. Yine durumu 'geleceğin metafizik 


\section{AJIT-e Bilişim Teknolojileri Online Dergisi \\ Academic Journal of Information Tecnology \\ 2021 Fall/Güz - Cilt/Vol: 12 - Sayı/Issue: 47 \\ doi) 10.5824/ajite.2021.04.003.x}

melankolisi' olarak tanımlayan Schmid'e göre, böylesi depresif tavrın arkasında, işlerin düzeltilemeyecek kadar ilerlediği varsayımının tetiklediği bir çaresizlik tecrübesi ve çıkışsızlık ihtimali de yatmaktadır. Üstelik burada yıkıcı bir düşmanın eli değil; bizatihi insanın kendini yok etme potansiyeline vurgu yapılmaktadır.

Anders'e göre dünyanın anlamsızlığına kadar vardırılan bu nihilist sızlanma, endüstri çağının evrensel depresyonudur (2018a, s. 227). Chul-Han'ın yaklaşımında bu melankoli, karşıkonulmaz bir değişimin değil; özü itibariyle yitirmişlik duygusunun bir çıtısı; ilişki içinde olduğu ama yanında bulamadığı bir olumsuzluğun, bağsızlığın ve yerçekimsizliğin sonucudur (2020, s. 42). İlginç bir şekilde melankolik öznenin tüm sadakati tam da bu kayıp nesneye ya da insanlık durumuna yöneliktir (Zizek, 2013, s. 133). Bu yitikliğin zamansal kökleri bu nedenle çoğu kez hatıraların biriktirildiği maziye uzanmaktadır. Zor seçimlerin dayatıldığı belirsiz bir gelecek imgesi karşısında, yaşanmış ve hafızanın tüm yorumlamalarına açık bırakılmış, güvenilir bir geçmiş duygusuna sığınmak geçerli olsun ya da olmasın olabildiğince anlaşılabilir bir yönelim olsa gerektir.

\section{ARAÇLARIN EGEMENLİĞİNDE}

Jacques Ellul'un (2003, s. 29) medeniyetimizi bir 'araç medeniyeti' olarak tanımlamasının üzerinden geçen yıllar, bu tespitin doğruluğunu onaylamış gibi görünmektedir. Ellul'dan sonra bu çağı 'nesneler çağı' olarak tasvir eden Baudrillard ise ayrıca şunları ekler: "Söylemek istediğim, nesnelerin ritmine ve onların hiç kesintisiz art arda gelişine göre yaşadığımız. Geçmiş uygarlıkların tümünde dayanıklı nesneler, araçlar veya binalar kuşaklarca insandan daha uzun yaşamışken, bugün onların doğmasını, gelişmesini ve ölmesini izleyen bizleriz" (2013, s. 16). Üstelik, yine Ellul'un vurguladığ1 gibi (2003, ss. 150-151), bedava bir şeyin kalmadığı, yalnız kalan kişinin ise asalak addedildiği bu araçlar medeniyetinin kuşatmasından kendini muaf kılmış insansız inziva mekanı da artık kalmamış gibidir. Nitekim tekniğin özerkliği, çağın insanını kendi seçimini yapmaktan alıkoymaktadır (Ellul, 2003, s. 151). Doğrusu Ellul'un bu keskin bakışında, insan ile teknik arasında bir ikilik bile söz konusu değildir. Şöyle ki, "artık insanın sadece üretken faaliyetini değil tüm faaliyetlerini ele geçirmiş" (Ellul, 2003, s. 14) "teknik, insanınki dahil hayatın her alanına girdiğinde insan için dışsal olmaktan çıkıp onun bizzat özüdür. İnsanla artık yüzyüze değildir; onunla bütünleşmiştir" (Ellul, 2003, s. 16).

Bir adım ötede teknoloji, kullanıcılarını araçsallaştırmaktadır. Bu nedenle Leonhard, insanları, ironik bir şekilde, "teknolojinin üreme organları" olarak tanımlamaktadır (2018, s. 83). Açık bir suistimale dönüşen bu yer ve rol değişimi, çağın insanını ya üretici ya da tüketici olarak teknolojinin bir çıtısı olmaya mahkum etmektedir. Kesin bir disiplin geleneği içinde şekillenmeyen bu mahkumiyet, dolaylı bir ödül ve ceza sistemi içermektedir. Şöyle ki, teknolojiyle irtibat çemberinin herhangi bir noktasında yer alması, modern bireyi içinde 
yaşadığı dünyanın (sanal da olsa) bir parçası yaparken; onu tahammül edilmesi güç bir yalnızlık hissiyle yüzleşmekten kurtarmaktadır. Fakat bunun karşılığında modern insanlık, sürekli buluş yapma mecburiyeti gibi bir mengenenin içine düşmektedir (Pierre ve Jacquard, 1995, s. 29). Sonuç olarak hiçbir araç, başlangıçtaki vaadine mutabık olarak, yalnızca bir araç olarak kalmamakta ve kendisini geçerli yapan her amacı kendi uğrunda mübah kılmaktadır (Anders, 2018a, s. 122). Bu bakımdan, yine Anders (2018b, s. 345), teknolojiye tarihin salt öznesi olarak değil; ereği olarak da yaklaşmaktadır.

lllich'e göre (2015, s. 62) araçların amaçlara dönüşmesi, bir bütün olarak teknolojinin doğasında değil; özelde "yanlış teknoloji” kavramında vücut bulur. Bir özne - nesne karmaşası olarak da beliren bu ikilemde, özne olmak mutlak bir hakimiyeti ifade etmediği gibi, nesnelik de hakikatin üstünde bir yerde düşünceyle suç ortaklığ yapacak denli güçlü bir aktifliğe gönderme yapmaktadır (Baudrillard, 2012, s. 23). Diğer yandan araçların sicilini temize çeken uygulayıcı / buluşsal bilim de -tıpkı modern insanın kendisi gibi- tekniğin aracı haline gelmiştir (Ellul, 2003, s. 20). Virilio'ya göre (2021, s. 8) böylesi bir bilim, kendisini doğasından uzaklaştıran teknolojik maceracılık batağına çoktan saplanmış haldedir. Bu nedenle, bilim ile kurgu arasındaki boşluk her geçen gün biraz daha kapanmaktadır.

Bilim kurgu, izleyiciyi teknik ve algısal olarak geleceğin olası değişimlerine hazırlamakta, inandırmakta ve onun bir parçası yapmaktadır. Bilim kurgunun benzer etkisine dikkat çeken Batukan, bu yolla geleceğin zihinlerimizde çoktan inşa edildiğini ve edilmekte olduğunu öne sürmektedir (2017, s. 74). Gerçekten de bilim kurgu [filmleri], gösterdiği şeyi yalnızca tahayyül etmekle yetinmeyip; derinden derine tayin de etmektedir. Üstelik hiçbir şekilde gerçekçi olma iddiası taşımaksızın. Belki de gerçeklik dediğimiz şey, bilim kurguyu takip etmektedir. Gelinen noktada gerçekçilik arayışı filmlerin değil; insanların [izleyicilerin] çabası olmaktadır. Her halükârda, Frank Furedi'nin tespit ettiği gibi, gerçeği bilim kurgudan ayıran çizgi de giderek belirsizleşmekte (2001, s. 7) ve bilim kurguya özgü konular toplum tarafından birer gerçek olarak kabul görmektedir (2001, s. 64).

Uzun yıllardır hayal dünyasının fantastik yansıması olagelen bilim kurgu, bir edebiyat ya da film türü olmasının ötesinde - geldiğimiz tarihsel dönemeç itibariyle- modern bireyin bizatihi içine düştüğü dünyanın kendisine dönüşmektedir. Diğer bir ifadeyle, bilim kurguda fantezileşen gelecek tasavvurları, artık belli bir mesafeden izlenen değil; içinde hemen herkesin bir şekilde rol aldığı hikayeciklerden oluşmaktadır: Sanki gelecek gelmiştir. Bunun nedeni, bilimsel ve sanatsal kurgunun ellerindeki geleceğin beklenen bir zaman dilimi olmaktan da çıkıp; istatistiki verilerle hesaplanan (yani tahminlerle öngörülen değil!) ve detaylıca tasarlanan (yani yüzeysel olarak varsayılan değil!) somut bir projeye evrilmiş olmasıdır. Bu hesaplama ve tasarıların ne denli kusursuz olduğu, dahası olası kusurların nelere mal olduğu ve insan/lığa ne tür nimetler veya lanetler bahşettiği, bu çalışmada da sorgulandığı üzere, konsensüse varılması muhal, müphem bir meseledir. Açı olan şu ki, bilim 


\section{AJIT-e Bilişim Teknolojileri Online Dergisi \\ Academic Journal of Information Tecnology \\ 2021 Fall/Güz - Cilt/Vol: 12 - Sayı/Issue: 47 \\ doi) 10.5824/ajite.2021.04.003.x}

kurgu anlatılarıyla harmanlanan bu yeni dünya tasarısında gelecek, bizden uzak bir zamansallıktan ziyade; üstünde gezindiğimiz bir uzama gönderme yapmaktadır.

\section{FÜTÜRIZZM KARŞISINDA BEŞERÎ BİLIMLER}

Bilimin ve kurgunun temel perspektifi olan fütürizm, geleceğe dair dönüşümün merkezine genellikle teknolojiyi koymaktadır. Birçok distopik anlatıda gündelik yaşama masumane bir sessizlik içinde giren aygıtların öngörülmez bir evrede kontrolden çıkmasının getirdiği katastrofinin yansımaları vardır. Leonhard'a göre (2018, s. 53), paradigma kayması yaşatan her dönüşüm ilk başta "yavaş yavaş" görünmekte; etkisini ise "birdenbire" göstermektedir. Böyle olduğu için, Lee (2019, s. 24) çoğu gerçeği, sanki hep orada varmış gibi kabul etmek yerine, nasıl birer gerçek haline geldiklerini anlamayı önermektedir. Fakat süreci, sonuçlarından tümüyle bağımsız bir izlek olarak takip etmek -geçerli bir çıkarım yapmak adına verimli bir yöntem olmayacaktır. Bu amaçla sürecin de mihenk taşlarını tanımlamak gerekebilir. Genellikle parça-olaylarda, anlarda, temsil-araçlarda ya da detay-söylemlerde karşılık bulan bu mihenk taşları, yine beşeri bilimlerin (humanities) şeyler-arası-ilişkileri önceleyen metodolojik niteliğiyle çözüme kavuşturulabilmektedir. Örneğin izlenimci düşünür Georg Simmel'in uyguladığı gibi (2020), anları, ayrıntıları ve yüzeysellikleri en derin, en bütüncül ve en esaslı hareketlerin menşei olarak görme yaklaşımı da bu şeyler-arasıilişkinin açılımını sağlamaktadır.

Şurası açık ki araçların dünyasında yükselen her beklenmedik değişim, toplumsal düzenin işleyişini radikal bir şekilde etkilemektedir. Buna rağmen, paradoksal olarak teknoloji hakkında yaygın mitlerden biri, onun ahlaki açıdan nötr olduğu inancıdır (Bauchspies, Croissant ve Restivo, 2019, s. 139). Oysa tasarımından uygulamasına hiçbir teknoloji ne kendi iç sisteminde ne de toplumsal izdüşümlerinde bulunduğu yeri olduğu gibi bırakmaktadır. Aksine, modern zamanlarda özellikle de kıyametin dört atlısı denen nanoteknoloji, biyoteknoloji, bilgi teknolojileri ve bilişsel bilimler ekseninde çağdaş küresel ekonominin en belirleyici dinamiğine evrilmektedir (Braidotti, 2018, ss. 77-78). Leonhard ise bu megadönüşümün paradigmalarını dijitalleşme, mobilleşme, ekranlaşma, aracısızlaşma, akıllanma, otomasyon, sanallaştırma, sezinleme ve robotlaşma olarak sınıflandırmaktadır (2018, s. 53). Tüm bu ve benzer sinıflandırma ve alt-başlıklandırmalar, teknolojide yoğunlaşmış gibi görünen sorunun esasında bir "insan sınırı sorunu" olduğunu değiştirmemektedir (Ellul, 2003, s. 19). Bu bile kendi başına beşerî bilimlerin teknolojiyi anlama ve anlamlandırma, yeri geldiğinde ise kıyasıya eleştirmesinin gerekçesini açıklamaya yetmektedir.

Böyledir, çünkü teknoloji ve onun arkaplanını teşkil eden bilimsel araştırmalar, bir hedef ve çıtı olarak sosyal inşalardır (Bauchspies, Croissant ve Restivo, 2019, s. 13). Beşerî bilimlerin yaşamın dört bir köşesine sinmiş ve tesir etmiş bir meseleye bu denli ilgi göstermesi, elbette onun salt merak duygusunu tatmin etme isteğine dayanmamaktadır. Aksine bu, beşerî 
bilimlerin meseleye müdahil tüm parametreleri hesaba katmayı şart koşan disiplinlerarası tabiatıyla ilgilidir. Melez bir ortamda tüm tarafları dikkatlice hesaba katmak ve önyargısızca ya da en azından insanlığın lehine yaklaşımla disiplinlerarasılığı sağlamak hiç de kolay değildir (Bauchspies, Croissant ve Restivo, 2019, s. 22). Yine de tüm taraflara temas edecek beşerî bilimsel tavır, fütüristlerin aksine, gücünü geleceği tahmin etme hedefinden almamaktadır. Roland Barthes için beşerî bilimlerin kırılganlığını temsil eden bu durum (2015, s. 55), örneğin Bauman'a göre -sosyoloji özelinde- beşeri bilimlerin görev ve mesuliyeti de değildir.

Şöyle der Bauman: “Sosyoloji bize geleceğin nasıl olacağını söyleyemez ... O, bize toplumumuzun gelecekteki şekli hakkında kesinlik vaad edemez... Sosyoloji, bizi, günümüzün zaten aşikâr olan eğilimlerinden, bu eğilimlerin kendi hallerine bırakıldığında işleri ne duruma getireceklerinden ve toplumun içinde bu tarz eğilimleri mevcut doğrultularında çalıştıran güçlerden haberdar ederek seçimimizi bilgilendirir". (2015, ss. 122123). Yine Bauman'ın yaklaşımına göre (2019, s. 306), farklılıkları kendi potasında eritmiş, sefaletten uzak bir özgürleşmenin önkoşulu olan bu seçimi sunan sosyoloji, tam da hazırlamaya çalıştı̆̆ı özgürlük arayışının mahsulü olduğu için yansız da ol(a)mayacaktır. Bu nedenle gelecek zaman tasavvurlarında beşerî bilimlerin duruşu, doğa bilimlerinin sayısal verilerle dayanaklandırılmaya çalışılan kesinlik arayışından farklı; hatta çoğu kez ona zıttır.

Artık birçoğu teknoloji kullanıcısı olan insanları zihinsel vizyonun reel ya da sürreal tüm uç noktalarını resmederek geleceğe adapte eden fütürist bilim kurgu kültürünün karşısında beşeri disiplinler, hıza müptela olmuş tekno-bilimsel çağı dur(ul)maya davet etmektedir. Bu yavaşlama, içinde düşünme, olası sonuçları sezinleme, sorgulama, yüzleşme ve revize etme eylemlerini içermektedir. Alain Badiou'ya göre de (2015, s. 34) örneğin felsefe, hız ve tutarsızlığın damgasını taşıyan dünyamızı olumlu anlamda kesintiye uğratarak üzerine tefekkür etmenin fırsatını sunmaktadır. Ne var ki beşerî bilimler belki de bunun sonucu olarak çağcıl ilerlemeciliğin karşısında, süreci geriye götüren atıl, ahlakçı, romantik, hatta radikal bir girişim olarak okunabilmektedir (Demir, 2020, s. 1538). Bu algılanış, 21. yüzyılda beşerî bilimlerin Avrupa üniversitelerinin müfredatından çıkartılma tehlikesiyle karşı karşıya olduğu fikrini dahi akla getirebilmektedir (Braidotti, 2018, s. 22).

Beşerî bilimcilerin bu anlamda banal bir şekilde "teknoloji karşıtı" olarak etiketlenebilmeleri yeni bir durum değildir. Anders'e göre bu itham, yalnızca teknolojinin önünü açmamakta; ayrıca eleştirmenin dilini felç edip, entelektüel anlamda tüm duruşunu etkisiz hale getirmektedir (2018a, s. 14). Üzerine düşünmenin ve yazmanın hem elzem hem popüler hem de güç olduğu böylesi bir zeminde, kitleleri karşı-eyleme geçmeye teşvik etmek ne kadar mümkündür? Jacques Ellul' da benzer soru şu şekilde sorulur: "Bizatihi insan üzerine harekete geçmek mümkün değil midir?” (2003, s. 353). Böylesi bir eylemselliğin sadece fikri aydınlanma meselesi olmadığı açıtır. Çünkü düşüncenin eyleme dönüşmesini sağlayan insan iradesi de aynı modern kültürün ürettiği konfor ve hazlarla kendinden geçmiş görünmektedir. 


\section{AJIT-e Bilişim Teknolojileri Online Dergisi \\ Academic Journal of Information Tecnology \\ 2021 Fall/Güz - Cilt/Vol: 12 - Sayı/Issue: 47 \\ doi) 10.5824/ajite.2021.04.003.x}

Bireyin kendi istenciyle, içinde yaşadığı toplumla ve parçası olduğu doğayla bağları kopmuş gibidir, ki Alain Touraine'e göre bu kopuş, tam da modernlik tarihinin özetidir (2002, s. 174).

Öte yandan bu kopuş, daha önce de belirtildiği gibi belli bir yavaşlık / gizlilik / sessizlik içinde cereyan ettiğinden ve sonuçları belirene kadar fark edilmeyen bir durum olduğundan ötürü, Bauman'a göre (2019, s. 168), tarif edilmesi mümkün olduğu ana kadar tanımlanamayan da bir sorundur. Yol almak için somut dayanaklara bağlı olan ve bu nedenle izsürücülükte gecikebilen beşerî bilimlerin, yeri geldiğinde bilim kurgu eserleri gibi fütürist çalışmalardan ve hatta komplo teorilerinden beslenmesinin nedeni budur. James Bridle da yeni karanlık çağın anlaşılmasında bu komplo teorilerini hafife almamakta ve onları "çağımızın hâkim anlatısı, ortak dili" olarak tanımlamaktadır (2020, s. 220). Gerek fantastik gerekse ürkütücü bir gelecek zaman imgesi oluşturulmasının önünü açan şey, Ellul'un tespit ettiği gibi (2003, s. 449), teknolojinin yaklaşık iki asır öncesine kıyasla artık iyice soyutlaşması, zımnileşmesi ve amaçlarından sapmış olmasıdır. Bu sürekli sapma, esasında kendi içinde tutarlı bir süreklilik arz etse de araçların egemenliğinin neden ve sonuçlarının yorumlanmasını güçleştirmekte; biraz da bu nedenle bilim ve kurguyu birbiriyle simbiyotik bir ilişki içine sokmaktadır.

\section{SONUÇ}

Çağın insanı, an itibariyle, görüntüler dünyasının hem "izleyicisi" hem de "izleneni" dir. Tıpkı fotoğraf karesini oluşturan ama tek başına da anlam üretemeyen pikseller gibi. Seyirlik obje ve nesne olarak insan, gördüğü ve göründüğü nispette onaylanmakta ve varolduğuna inanmaktadır. Anders'in yetkin bir şekilde işaret ettiği gibi (2018a, s. 129), görüntüler gerçek yerine konurken; gerçek de görüntü halini almaktadır. Tam da bu nedenle, bilim kurgu, zamanın en toplumsal gerçekçi sineması olmaya namzettir. Peki "izleyiciler olarak" geleceği anlama ve yönetme kaygımızın arka planında ne vardır? Bunun arkasında izleyici/cilik merakı ve daha mühimi, geleceğin uyumlu bir parçası olma mecburiyeti ya da istenci yatmaktadır.

Gerçeğin de bilim kurgulaştığı çağdaş kültürde hemen tüm deneyimler küresel bir sistem içinde devinmektedir. Bridle'a göre de (2020, s. 59), "ağ bağlantılı dünyada yerel sonuç diye bir şeye yer yoktur". Tekno-bilimin ellerinde gerçekleşen "ilerleme", olanca kontroldışı yıkıcılığına rağmen; tüm meşruiyetini günümüzün bilgi üretimine yapılan yatırımların büyüklüğünden almaktadır. Bu nedenle Hannah Arendt, bizim toplumumuzun büyümekten anladığ1 şeyin "geleceğe doğru gidiş" olduğunu belirtirken haklıdır (2020, s. 170). Yüzünü tümüyle geleceğe dönmüş bu ilerlemecilik, Leonhard'ın ifade ettiği gibi (2018, s. 58) "yapabildiği için yapması gerektiğine inanmış" tekno-bilimin pragmatist stratejilerinde şekillenmektedir. Fakat Leonhard, tam bu noktada endişeli bir biçimde kritik de bir soru ekler: "Sırf ilerleyebiliyoruz diye ilerlemekten kaygı duymamalı mıyı?" (2018, s. 91). Yıllar önce teknolojik anlamda politik ve ahlaki problemlerin belirginleşmeye başladığı dönemde önemli 
düşünür Lewis Mumford, böylesi bir soruya karşılık "makinenin doğasında ve teknisyenin aldığı eğitimde bize yeterli cevap sağlayacak hiçbir şey olmadığının" altını çizmiştir (2017, s. 556).

Aynı soruda "Pekâlâ ne yapmalı?" umudunu da baltalayan çetin bir çıkmaz söz konusudur. Çünkü her şeyden önce günümüz insanına dair birçok kabul idealleri, tıpkı olağanüstü bilim kurgu kahramanları gibi makinelere öykünmeye veya Ellul'un altını çizdiği gibi (2003, s. 349) makinesel mükemmelliğe ulaşmaya zorlanmaktadır. İnsani kusurların her an vurgulanıp; zamanın da müphemleştiği bu 'sürekli uyumlanma' girdabında modern insan, hayallerinden düşüncelerine, eylemlerinden ilişkilerine bir makine sisteminin işleyişini andırmakta, çünkü onu yinelemektedir. Goodman (2016, s. 556), gelinen bu aşamayı makinelerle olan ilişkimizin (ya da -bana göre- benzerliğimizin) belki de son dönüm noktası olarak görmekte ve insanları bu açmazı sorgulamaya davet etmektedir. Harari soruyu şöyle revize etmektedir: “Neyi istemek istiyoruz?" (2015, s. 406).

Leonhard aynı perspektifte şunları söyler: "Algoritmalara harcadığımız zamanı ve kaynakları bizi insan yapan değerlere de harcamazsak teknoloji yalnızca hayatlarımızı yönetmekle kalmayacak, dahası bizzat bizler teknolojiye dönüşmeye zorlanacă̆ız, kandıralacağız ya da buna razı edileceğiz. Araçlarımızın araçları olmuş olacağı"' (2018, s. 190). Seçim, irade ve özgürlük gibi insana dair en kadim kavramları da kuşatan bu yeni ama marjinal sorunsal karşısında yönetmen Andrei Tarkovski, biraz da çözüm önerisi olması bakımından şu tespitte bulunmaktadır: "Acı olan, bizim gerçekten özgür olmayı bilemeyişimiz. Bizler, bedelini başkasına ödettiğimiz bir özgürlük istiyor, başkaları adına isteklerimizden vazgeçmediğimiz gibi, bunu kişisel haklarımıza ve özgürlüklerimize yapılan bir saldırı olarak görmekten çekinmiyoruz. Bugün, her birimizin en belirgin özelliği aşırı bireyciliğimizdir. Fakat özgürlüğü burada aramak boşuna. Özgür olabilmemiz için, hayattan ve çevremizdeki insanlardan bir şey beklemek yerine önce kendimizden talep etmesini öğrenmeliyiz" (2000, s. 204).

Ne var ki, insan için 'en kısa yol' olarak görülebilecek 'kendiyle ilişki' veya 'kendinden talep etme' edimleri, an itibariyle varlığın en çetrefilli ve karmaşık güzergahına dönüşmüştür. Nitekim modern insanın kendi varlığına uzanan yolları, araçların temin ettiği konfor ve alışkanlıklar tarafından çoktan bastırılmıştır. Daha açık bir ifadeyle, artık modernlerin kendileriyle aralarındaki bağ, dolaysız bir yakınlığı değil; teknolojik tasarımın ellerinde şekillenen ve araçlarla istiflenmiş devasa bir uzaklığı ifade etmektedir. Belki de bu nedenle modern karakter için kendi içine yönelmek, kendi içinde kalmak, orada vakit geçirmek ve orayı imar etmek söylemde en yaygın, eylemde en az tercih edilen tavra dönüşmüştür. Ve yine belki de bu nedenle modern birey, enerjisini en fazla dış dünyanın yığıntılarını taşıyan araçlarla harcamaktadır. Kendisini kuşatan yeni fütürist gerçekliği ve iyiden iyiye içine düştüğü geleceği duyumsamak için -yine dışsal bir eylem olarak- bilimin ve kurgunun anlatılarına bu denli yoğunlaşması da belki bundandır. 


\section{AJIT-e Bilişim Teknolojileri Online Dergisi \\ Academic Journal of Information Tecnology \\ 2021 Fall/Güz - Cilt/Vol: 12 - Sayı/Issue: 47 \\ doi) 10.5824/ajite.2021.04.003.x}

\section{KAYNAKÇA}

Anders, G. (2018a). İnsanın Eskimişliği: İkinci Endüstri Devrimi Çağında İnsan Ruhu Üzerine (1. cilt)

(H. Ertürk, Çev.). İthaki Yayınları.

Anders, G. (2018b). İnsanın Eskimişliği: Üçüncü Endüstri Devrimi Çă̆ında Yaşamın Tahribatı Üzerine

(2. Cilt). (H. Ertürk, Çev.). İthaki Yayınları.

Arendt, H. (2020). Geçmişle Gelecek Arasında (B. S. Şener, Çev.). İletişim Yayınları.

Badiou, A. (2015). Gerçek Mutluluğun Metafiziği (M. Erşen, Çev.). Monokl Yayınları.

Barthes, R. (2015). Bir Deneme Bir Ders: Eiffel Kulesi ve Açılış Dersi (M. Rifat ve S. Rifat, Çev.). Yapı Kredi Yayınları.

Batukan, C. (2017). Robo-Tizm: Robot, Android, Sayborg ve Yapay Zekada Ruh Üzerine. Altıkırkbeş Yayın.

Bauchspies, W. K.; Croissant J., ve Restivo, S. (2019). Bilim Teknoloji ve Toplum Sosyolojik Bir Yaklaşım (B. Kuryel, B. Balkız ve Ü. Tatlıcan, Çev.). Phoenix Yayınevi.

Baudou, J. (2005). Bilim-kurgu (İ. Bülbüloğlu, Çev.). Ankara: Dost Kitabevi.

Baudrillard, J. (1998). Simülakrlar ve Simülasyon (O. Adanır, Çev.). Dokuz Eylül Yayınları.

Baudrillard, J. (2006). Cool Anılar V (A. Sönmezay, Çev.). Ayrıntı Yayınları.

Baudrillard, J. (2010). Sanat Komplosu: Yeni Sanat Düzeni ve Çă̆daş Estetik. (E. Gen ve I. Ergüden, Çev). İstanbul: İletişim Yayınları.

Baudrillard, J. (2012). Imkansız Takas. (A. Sönmezay, Çev.). Ayrıntı Yayınları.

Baudrillard, J. (2013). Amerika (Y. Avunç, Çev.). Ayrıntı Yayınları.

Bauman, Z. (2015). Özgürlük (K. Eren, Çev.). Ayrıntı Yayınları.

Bauman, Z. (2019). Akışkan Modernite (S. O. Çavuş, Çev.). Can Yayınları.

Braidotti, R. (2018). İnsan Sonrası (Ö. Karakaş, Çev.). Kolektif Yayıncllık.

Bridle, J. (2020). Yeni Karanlık Çağ \& Teknoloji ve Geleceğin Sonu (K. Güleç, Çev.). Metis Yayınları.

Bukatman, S. (1993). Terminal Identity: The Virtual Subject in Post-Modern Science Fiction. Duke Universtiy Press.

Chul-Han, B. (2017). Yorgunluk toplumu (S. Yalçın, Çev.). Açılım Kitap.

Chul-Han, B. (2019). Zamanın Kokusu: Bulunma Sanatı Üzerine Felsefi Bir Deneme (Ş. Öztürk, Çev.). Metis Yayınları.

Chul-Han, B. (2020). Şiddetin topolojisi (D. Zaptçığlu, Çev.). Metis Yayınları.

Demir, S. T. (2020). Tekno-Bilimsel İlerlemecilik ve Nostaljik-Gelişmecilik İkileminde Modern İnsan. Beytulhikme: An International Journal of Philosophy, 10 (4), 1537-1557. 
Demir, S. T. (2021). Büyüyen Veri Küçülen İnsan: Şimdileşen Geleceği Kara Ayna'da Seyretmek. TRT Akademi, 6 (11), 88-105.

Diken, B., ve Laustsen, C. B. (2016). Filmlerle Sosyoloji (S. Ertekin, Çev.). Metis Yayınları.

Ellul, J. (2003). Teknoloji Toplumu (M. Ceylan, Çev.). Bakış Yayınları.

Furedi, F. (2001). Korku Kültürü: Risk Almamanın Riskleri. (B. Yıldırım, Çev.). Ayrıntı Yayınları.

Gadamer, H. (2015). Güzelin Güncelliği: Oyun, Sembol ve Festival Olarak Sanat F. Tepebaşılı, Çev.). Çizgi Kitabevi.

Goodman, M. (2016). Geleceğin Suçları: Dijital Dünyanın Karanlık Yüzü (C. Özdemir, Çev.). Timaş Yayınları.

Guenon, R. (2019). Modern Dünyanın Bunalımı (M. Kanık, Çev.). İnsan Yayınları.

Harari, Y. N. (2015). Hayvanlardan Tanrılara Sapiens: Insan Türünün Kısa Tarihi (E. Genç Çev.). Kolektif Kitap.

Harari, Y. N. (2018). 21. Yüzyıl İçin 21 Ders (S. Siral, Çev.). Kolektif Kitap.

Heidegger, M. ve Lovitt, W. (1977). The Question Concerning Technology and Other Essays, Harper and Row.

Horkheimer, M., ve Adorno, T. W. (1996). Aydınlanmanın Diyalektiği Felsefi Fragmanlar (O. Özgül, Çev.). Kabalcı Yayınevi.

Illich, I. (2015). Şenlikli Toplum (A. Kot, Çev.). Ayrıntı Yayınları.

Kracauer, S. (2011). Kitle Süsü (O. Kılıç, Çev.). Metis Yayınları.

Lee, E. A. (2019). Dijital Ruh: Insan ve Teknoloji Arasındaki Yaratıcı Ortaklık (A. Uysal ve G. Uysal, Çev.). İstanbul: Koç Üniversitesi Yayınları.

Leonhard, G. (2018). Teknolojiye Karşı İnsanlık: Insan ile Makinenin Yaklaşan Çatışması. (C. Akkartal ve İ. Akkartal, Çev.). Siyah Kitap.

Lukacs, J. (2018). Modern Çă̆ın Sonu (İ. Kapaklıkaya, Çev.). Ketebe Yayınları.

Mumford, L. (2017). Teknik ve Uygarlık (E. C. Ercan, Çev.). Açılım Kitap.

Pierre A. ve Jacquard, A. (2015). Mutlak (M. Yakupoğlu, Çev.). Yapı Kredi Yayınları.

Ranciere, J. (2016). Bela Tarr, Ertesi Zaman (E. Karakaya, Çev.). Lemis Yayınları.

Simmel, G. (2020). Bireysellik ve Kültür (T. Birkan, Çev.). Metis Yayınları.

Standage, T. (2021). 'Geleceği Tahmin Etmeye Yarayacak bir Alet Çantası', Mega-Tech: 2050'de Teknoloji, Daniel Franklin (Ed.). (B. Şeyrek, Çev.). Siyah Kitap.

Toffler, A. (1991). Ekonominin Çöküşü: Eko Spazm (M. Akçok, Çev.). İnsan Yayınları.

Toffler, A. (2008). Üçüncü Dalga (S. Yeniçeri, Çev.). Koridor Yayıncılık.

Toffler, A. (2011). Şok / Gelecek Korkusu (A. S. Sargut, Çev.). Koridor Yayıncılık. 
Touraine, A. (2002). Modernliğin eleştirisi (H. Tufan, Çev.). Yapı Kredi Yayınları.

Virilio, P. (2021). Enformasyon Bombası (K. Şahin, Çev.). Metis Yayınları.

Zizek, S. (2013). Biri Totalitarizm mi Dedi? (H. Nalçaoğlu, Çev.). Epos Yayınları. 